THURSDAY, MARCH 20, 1879

\section{ROYAL AGRICULTURAL COLLEGE, CIRENCESTER}

D

URING the last few years the question of Agricultural Education has been very fully and fruitfully discussed. The experiment of an examination in the principles of agriculture, under the Science and Art Department, had an unexpected success; and showed that there was throughout the kingdom a demand for instruction in agricultural matters. At the present moment efforts are being made to satisfy this demand more completely by means of local organisation for developing and extending the facilities already offered by the Science and Art Department.

There is at Cirencester a college founded specially for the advancement of agricultural education. It has oneor more-Royal Charters; it has the power of granting diplomas; it is under Royal patronage, and bas the advantage of being managed by numerous Earls and M.P.s. This institution ought to (and might) have been the centre of the movement to which allusion has been made; but, unfortunately, its own troubles seem to be enough to occupy the whole attention of the Committee of Management; and, for the second time in the bistory of the college, threaten to bring about its extinction. For the past few weeks the agricultural press has been teeming with letters and articles headed "Professor Church and the Royal Agricultural College." The facts, as to which there seems to be no dispute, are briefly these :-Prof. Church is about to be married. Other professors, his colleagues and juniors, had done the same, and nonresidence in their cases was not found incompatible with the proper performance of their several duties; as a matter of fact each of Prof. Church's predecessors was non-resident. Yet the Principal intimated to Prof. Church that without residence he could "no longer discharge the duties of Professor of Chemistry in this college." It appeared that this decision on the part of the Principal was not authorised under the bye-laws: such a point could be determined only by the Committee of Management; and the case was referred to them. The result was, however, unaltered. While "fully sensible of the services rendered by Prof. Church during his sixteen years' residence in the College," the Committee "regret that they cannot accede to his recent proposal of non-residence." The consequence of this was two resignations. Prof. Lloyd Tanner regarding the decision " as showing that neither long and zealous performance of duty, nor special ability for work are duly recognised," has resigned the Chair of Mathematics and Physics; and Prof. Fream, "as the only protest it is in his power to make against the treatment his colleague has received," similarly vacates the Chair of Natural History.

Such are the circumstances under which the three senior resident professors at Cirencester College are leaving. Other matters have rendered the affair even more painful than it need have been, but we believe the simple, undisputed facts of the case are amply sufficient to enable our readers to form a just opinion of the mode of managing Cirencester College. Those who intend to become candidates for the vacant chair have had an

Vor. XIX.-No. 490 opportunity of judging how one bye-law can be and is used against a man such as Prof. Church; we will only advise them to study the other bye-laws and guess how they may be used against younger and less known men. Having seen these bye-laws ourselves we are curious to know who will be induced to replace the vacancies just announced.

\section{PROF. HUXLEY'S HUNE}

Hume. By Prof. Huxley. (London: Macmillan and Co., I 879.)

DROF. HUXLEY has given a clear and succinct 1. account of the philosophy of Hume, in a style at once fresh and pointed. We should be thankful to him that, following the example of Locke and Hume himself, he discusses philosophical questions in :genuine and idiomatic English, and consistently: avoids the use of a lumbering phraseology, imported from abroad, amid which the thinking evaporates, for the most part, in pure verbalism. The volume before us is limited to a brief account of Hume's life and his philosophical opinions. It hardly touches what has been said on the other side in criticism or in correction of Hume' $s$ views. Here and there Prof. Huxley offers a criticism; but, though generally acute, it is seldom on anything but a point of detail. Indeed, the volume may be described as rather too much of a bare statement of Hume's principles and conclusions.

As Prof. Huxley may fairly be regarded as dogmatically accepting Hume's principles and boldly carrying them out to their results, while Hume may with proba. bility be regarded as having only hypothetically held the principles, we might have expected a fuller vindication of them than is at all attempted in the volume. On all the metaphysical questions of greatest moment Prof. Huxley's position is a negative one; and if, as it seems, he accepts Hume's principles absolutely, it is one of complete negation.

In the opening chapter on the Philosophy (Chap. II.) Prof. Huxley has done good service in clearly stating the terms of the question. He very properily points out that the question regarding the limits of knowledge, or "What we can know," is not a primary but a secondary question. He is emphatic in showing that it implies the previous questions as to what we mean by knowledge, and how we come by the thing we call knowledge. And he very well points out that these latter questions are psychological, and that psychology, accordingly, is the only proper basis of assertions about knowledge, whether these refer to its nature, conditions, or limits. This clear and vigorous statement is not inopportune, for there is somewhat of a tendency at present, very inconsistently indeed, to ignore psychology. We have professions of "deducing" the conditions of "experience." It seems strange that it does not occur to the advocates of such a method that its basis is necessarily an accurate examination of what experience or consciousness in its fullest extent is; what, in a word, is the thing spoken of, whose conditions it is proposed to evolve. This implies a full and scientific psychology-the only safeguard against fantastic system-making, otherwise the so-called "deduction" becomes a method of if and must" 